\title{
Erratum to: The dissolution of natural and artificial dusts in glutamic acid
}

Ling Zhang ${ }^{1} \cdot$ Faqin Dong ${ }^{2} \cdot$ Xiaochun $\mathrm{He}^{2}$

Published online: 8 April 2015

(C) Springer-Verlag Wien 2015

Erratum to: Miner Petrol

DOI 10.1007/s00710-014-0345-3

The original version of this article unfortunately contained mistakes in the authors' names due to the difference of expression about the family name between West and East. The authors' names are now correct as given in the list above.

The online version of the original article can be found at http://dx.doi.org/ 10.1007/s00710-014-0345-3.

\section{Faqin Dong}

fqdong@swust.edu.cn

1 School of Chemical Engineering, Xuzhou College of Industrial Technology, 1 Xiangwang Road, Xuzhou, Jiangsu, People's Republic of China

2 School of Environmental Resource and Engineering, Southwest University of Science and Technology, 59 Qinglong Road,

Mianyang, Sichuan, People's Republic of China 